\title{
Práxis e enunciação: Greimas herdeiro de Saussure ${ }^{*}$
}

Jacques Fontanille ${ }^{a}$

\author{
Tradução de: \\ Raíssa Medici de Oliveirab \\ Renata Cristina Duarte
}

\footnotetext{
*A presente tradução foi feita durante Estágio em Pesquisa no Exterior das doutorandas da UNESP Raíssa Medici de Oliveira (processo BEPE (FAPESP) n. 2016/197885) e Renata Cristina Duarte (processo BEPE (FAPESP) n. 2016/197879), estágio realizado na Université de Limoges (França), entre 01/03/2017 e 31/08/2017, sob a supervisão do Prof. Dr. Jacques Fontanille. A tradução teve revisão de Edna Maria Fernandes dos Santos Nascimento (Livredocente em Linguística pela UNESP/Docente no Programa de Linguística e Língua Portuguesa da UNESP-Araraquara).
}

\begin{abstract}
Resumo
A partir dos estudos saussurianos sobre o signo e sobre a dimensão práxica da linguagem, observase, no presente artigo, a constituição de uma teoria da enunciação semiótica e, mais precisamente, do conceito de práxis enunciativa. Tal noção refere-se às operações que, por meio de uma apropriação do sistema das estruturas profundas da narratividade, produzem configurações semióticas suficientemente estabilizadas para se colocarem à disposição de outros usos, as quais são apreendidas num movimento constante de remodelação das formas, sendo responsável, portanto, pela renovação dos discursos.
\end{abstract}

Palavras-chave: Saussure. Greimas. Semiótica. Signo linguístico. Práxis enunciativa.

\footnotetext{
a Professor emérito na Université de Limoges/França e fundador do Centre de Recherches Sémiotiques (CeReS); E-mail: jacques.fontanille@unilim.fr.

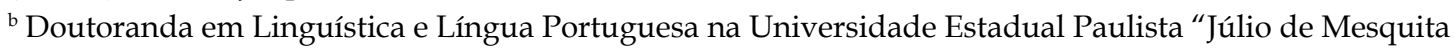
Filho" (Câmpus Araraquara); E-mail: raissamedici@yahoo.com.br.

'Doutoranda em Linguística e Língua Portuguesa na Universidade Estadual Paulista "Júlio de Mesquita Filho" (Câmpus Araraquara); E-mail: renatalari@yahoo.com.br.
} 


\section{Introdução}

A práxis enunciativa foi definida há cerca de trinta anos (Greimas e Fontanille ${ }^{1}$, Bertrand ${ }^{2}$, Fontanille e Zilberberg ${ }^{3}$ ) como compreendendo todas as operações que, por meio de uma apropriação do sistema das estruturas profundas da narratividade, produzem configurações semióticas suficientemente estabilizadas para se colocarem à disposição de outros usos, as quais são apreendidas, por essa mesma razão, num movimento constante de remodelação das formas. O esquema narrativo canônico é uma dessas formas, que, como se sabe, é característico das culturas europeias; as paixões e seu desdobramento sintagmático são outras, também marcadas por seu pertencimento cultural. A práxis enunciativa implica assim cadeias de operações, organizadas no tempo coletivo, e uma capacidade de criação e de renovação na produção das figuras do sentido, sob a coerção de condições culturais.

A práxis enunciativa rejeitou então os limites da textualidade: cada enunciação particular encontra-se em perspectiva na profundidade temporal de enunciações concomitantes, anteriores e até mesmo posteriores. Tanto as estereotipias como as inovações, tanto as menções retrospectivas como as menções prospectivas, todos esses movimentos da práxis enunciativa distendem a temporalidade própria ao texto e fazem-na participar de um regime temporal que pertence a

${ }^{1}$ GREIMAS, A. J.; FONTANILLE, J. Semiótica das Paixões: dos estados de coisas aos estados de alma. Tradução de Maria José Rodrigues Coracini. São Paulo: Ática, 1993.

2 BERTRAND， D $\mathrm{L}^{\prime}$ i m person e 1 de l'énonciation. Praxis énnonciative: conversion, convocation, usage. Protée. Théories et pratiques sémiotiques. Québec: Université du Quebec, v. 21, n. 1, p. 25-32, 1993.

${ }^{3}$ FONTANILLE, J.; ZILBERBERG, CL. Tensão e significação. Tradução de Ivã Carlos Lopes, Luiz Tatit e Waldir Beividas. São Paulo: Discurso Editorial: Humanitas/ FFLCH/USP, 2001. outro plano de imanência: aquele, precisamente, das práticas.

Mas essa concepção de enunciação não é uma invenção nem de Greimas nem da semiótica em geral: ela já havia sido fortemente afirmada por Saussure, que não propõe necessariamente uma teoria da enunciação, visto que a práxis faz parte, para ele, da vida dos signos e das línguas.

\section{Saussure: o signo é ação e transformação incessantes}

\section{Uma unidade dual ativa e instável}

O signo saussuriano é dual: uma "entidade psíquica de duas faces" que "une não uma coisa e uma palavra, mas um conceito e uma imagem acústica" (SAUSSURE, 2006, p. 80); ou ainda, é uma "associação de dois elementos igualmente imateriais, mas absolutamente diferentes" (GODEL, 1957, p. 
190, tradução nossa), uma "dualidade incessante", o "ponto de junção dos dois domínios", o "acoplamento de objetos heterogêneos" (SAUSSURE, 2004, p. 21-23). Essa dualidade é a fonte de instabilidade do signo, pois os signos não são dados prontos e acabados, e é necessário, a cada nova execução na fala, reunir suas duas faces em uma só unidade.

Saussure não cessa, no entanto, de afirmar, de maneira recorrente e mesmo obstinada, que essa unidade é indissociável, mas ela somente é indissociável no pensamento: só se pode pensar linguisticamente o signo como uma unidade. A essa indissociabilidade metodológica e "de pensamento", Saussure não deixa de opor a instabilidade efetiva, na realidade social e cultural, dessa mesma unidade do signo. A razão disso se deve simplesmente ao fato de que, na realidade social, a reunião das duas faces do signo é uma ação, que Saussure designa frequentemente como "execução" do sistema da língua, e que toma a forma de um processo coletivo:

A língua não oferece, sob nenhuma de suas manifestações, uma substância, mas apenas ações, combinadas ou isoladas de forças psicológicas, físicas, mentais. (SAUSSURE, 2004, p. 170)

Afirmação surpreendente para todos aqueles que leram Saussure pelo prisma de Hjelmslev ou da única vulgata estruturalista: nenhuma substância para moldar, mas ações inumeráveis. As "ações" em questão resultam de associações entre as forças e, desse modo, a práxis aqui invocada é a explicação de uma dinâmica das formas. Signo ou linguagem, a dualidade é ao mesmo tempo indissociavelmente formal de um lado (em pensamento) e ativa de outro (no social), e é nisso que sua dualidade é convenientemente "incessante" e se opõe a todo "repouso absoluto".

A alternativa "substância/ação" desapareceu em Hjelmslev: há somente a substância, e a ação é remetida ao processo. A substância está logicamente situada "antes" da forma, que constitui o sistema (a imanência), e que dá lugar em seguida ao processo (a manifestação). Logicamente, Greimas e Courtés reiteram no Dicionário (2013) que a manifestação pressupõe o sistema.

É necessário que examinemos mais atentamente essa relação da língua com o social e com o tempo, via práxis. Poderíamos pensar que a língua está inserida no social e no 
tempo e que, em suma, a práxis é exterior (numa realidade social e temporal) à própria língua. Mas Saussure diz o contrário:

É porque, em nenhum momento, contrariamente à aparência, o fenômeno semiológico, qualquer que ele seja, deixa fora de si mesmo o elemento da coletividade social: a coletividade social, com suas leis, é um de seus elementos internos e não externos, esse é o nosso ponto de vista. (SAUSSURE, 2004, p. 249)

A linguagem (Saussure não fala aqui da língua), sob todas as suas formas, é de natureza eminentemente práxica, e por consequência, o social está inserido na linguagem, e não no seu exterior.

O mesmo acontece com o tempo. Ele não intervém somente na execução do signo: o signo como unidade é portador de uma tensão temporal, produzida pela coexistência em seu interior do linear e do "instantâneo". O tempo está implicado na constituição do signo enquanto unidade biface, ele nunca está fora do signo.

\section{A práxis de transmissão}

No entanto, a língua e os signos, mesmo submetidos a essa práxis incessante, parecem relativamente estáveis e, ao mesmo tempo, tomados por uma mudança incontrolável. A estabilidade é obra da convenção: uma vez constituídas as formas, a práxis as estabiliza por convenção. Mas por que a convenção, uma vez estabelecida, não se mantém de modo imperturbável? Se a resposta a essa questão é fundada essencialmente no princípio da arbitrariedade, ela mobiliza também a problemática da transmissão.

Ainda que presente no Curso de Linguística Geral (CLG), a transmissão não possui ali, entretanto, o mesmo estatuto que nos escritos de Saussure. Apenas nos Escritos de Linguística Geral (ELG) vemos que, se a convenção social pode ser considerada como um fator de conservação, de estabilidade e de resistência à inovação, ela é também o suporte da alteração dos signos, graças ao movimento da relação entre significante e significado: esse paradoxo somente pode ser resolvido se nós levarmos em consideração a circulação e a transmissão dos signos e das línguas ao longo do tempo.

E ainda, longe de ser uma propriedade externa, a transmissão é uma práxis inerente à própria constituição do 
signo; não é nem um movimento provocado por uma força externa, nem uma propriedade independente de sua estrutura, mas sim um processo permanente situado no interior do signo, e que faz parte de sua constituição dual.

Essa será a reação capital do estudo da linguagem sobre a teoria dos signos, esse será o horizonte para sempre novo que ela terá aberto [...], ter percebido e revelado todo um lado novo do signo, a saber, que este só começa a ser realmente conhecido quando se percebe que ele é algo não apenas transmissível mas, por natureza, destinado a ser transmitido, modificável. Apenas para quem quer fazer a teoria da linguagem, é a complicação centuplicada. (SAUSSURE, 2004, p. 189)

A transmissão em questão é muito específica, pois ela recai sobre as relações, as negações e as diferenças. Em função disso, a transmissão está indissociavelmente ligada ao caráter convencional do signo e dota-o de uma perpétua "segunda vida":

O que há de particular no signo convencional é que as disciplinas que dele poderiam se ocupar não desconfiam que esse signo seja transmissível e, por isso, dotado de uma segunda vida, de onde se pode dizer que essas disciplinas, assim como o público (em geral), não têm noção alguma. (SAUSSURE, 2004, p. 197)

A identidade do signo não é outra coisa senão a aglomeração social das suas execuções: uma identidade diferencial, sócio-praxeológica, plural e interativa. O signo não é uma entidade naturalmente dada, nem criada para ser retomada e propagada (ou mesmo degradada), é uma "unidade" que perdura somente em razão da diversidade dos atos que a constituem, produzindo assim séries de variantes que são o único modo de existência em que é possível observá-lo e apreendê-lo, através de suas múltiplas execuções.

O momento fundador desse raciocínio é a substituição da substância pela ação: o signo não é uma abstração obtida pela discretização da substância, o signo é uma "classe de execuções", uma classe praxeológica. E como toda prática, esse "curso práxico" não tem nem origem nem fim pertinentes: pode-se teoricamente interrompê-lo, mas por natureza e por definição ele só pode "continuar". Vê-se exatamente o ponto de divergência entre o que se tornou a linguística estrutural (notadamente via Hjelmslev), ao refletir a passagem da 
substância à forma, e depois da forma imanente à manifestação, e o que ela poderia ter-se tornado se tivesse levado em conta a outra versão, a ação no interior do signo e do sistema.

Disso resulta, segundo o próprio Saussure, que: “o contrato primitivo se confunde com o que se passa todos os dias na língua", o que quer dizer que a origem do "contrato primitivo" se dilui em todos os momentos ao longo do curso da prática. É precisamente esse aspecto fundamental que é visado pela transmissão do signo: além de sua qualidade social, a convenção que o constitui, longe de ser um congelamento reificante, é uma espécie de "permanência social em circulação", em virtude da qual os signos são indefinidamente reconstruídos e experimentados como idênticos porque congruentes ou diferentes dos outros.

Nessa perspectiva, convenção e circulação dos signos não se sucedem, mas se superpõem, e em função disso a transmissão suspende e invalida a distinção entre estruturação dual do signo de um lado e comunicação de outro: os signos emergem e se realizam somente na interação. A transmissão não é então uma prova externa ao signo nem um atributo acessório ou complementar: ela resulta da "vida dos signos no interior da vida social", razão pela qual circulação, retomada e disseminação são inseparáveis da constituição dual, uma vez admitido que essa constituição dual implica uma dinâmica prática. Esse aspecto está, além disso, ligado ao fato de que o signo só se realiza e se transmite enquanto valor, o valor não podendo ser concebido independentemente da troca, das interações e do tempo.

É também na sua transmissão que o signo se realiza enquanto unidade em curso de variação constante, e como um fator de redistribuição dos valores dos outros signos. E é da sua natureza, como escreve Saussure, ser "destinado a ser transmitido", isto é, constituído para ser transmitido, e transmitido para ser constituído:

[...] constatemos, em seguida, a completa insignificância de um ponto de vista que parte da relação de uma ideia e de um signo fora do tempo, fora da transmissão, que sozinha nos ensina (experimentalmente) o que vale o signo. (SAUSSURE, 2004, p. 199) 


\section{Instabilidade e deslocamentos do valor, sociabilidade e temporalidade da troca}

A propriedade do signo de fazer fundir em seu interior instabilidade, alteridade e temporalidade, como base interna e ativa de sua própria alteração, permite que o processo da transmissão possa ser analisado tanto do ponto de vista sincrônico quanto do diacrônico. O já conhecido interesse que Saussure concedeu à questão do tempo não se resume assim a sua dimensão histórica. Mais precisamente, a problemática da transmissão mostra que a sincronia saussuriana não é uma acronia, contrariamente àquilo de que a vulgata estruturalista tentou nos convencer.

A sincronia é um ponto de vista metodológico sobre a língua; é também uma transposição do sentimento de estabilidade do sistema que os sujeitos falantes têm em dado momento, mas um sentimento apenas, o qual lhes permite crer que a intercompreensão é possível. A diacronia é outro ponto de vista sobre a língua e os signos, mas um ponto de vista que não tem o privilégio sobre o tempo. Pois se há realmente, segundo Saussure, uma característica permanente dos fatos de linguagem, é realmente aquela do processo de sua (re) estruturação interativa e temporalizada: pode-se apreendêla em sincronia, para construir as relações, as classes e os paradigmas a partir de séries de execuções práticas, e pode-se também apreendê-la em diacronia, para construir as regras de transformações e de reconfigurações. Mas, nos dois casos, o objeto é o mesmo, e só muda o ponto de vista.

Insistimos sobre o fato de que essa concepção da prática de transmissão é incompatível com uma concepção do signo como instrumento da comunicação, pois ela faz da mudança e da práxis um funcionamento interno ao sistema, e não um fenômeno que lhe seria aplicado do exterior: as transmissões sucessivas produzem inevitavelmente deslocamentos da relação entre significante e significado, deslocamento que não tem base externa e que é, finalmente, um contínuo (re) estabelecimento da convenção:

Mas nós não dissemos, eu reconheço, por que eles [os signos] têm que se alterar. É fácil indicar a razão dessa abstenção. Desde o início, eu estabeleci que havia fatores de alteração distintos, mas tão misturados em seu efeito que não é prudente separá-los no mesmo instante. Eu disse que o fato total só se traduziria, com segurança, pela expressão deslocamento da 
relação total entre significante e significado, esteja a alteração no significante, esteja ela no significado.

Então, nós consideramos a alteração sem separar suas causas e suas formas, porque há um certo perigo em querer fazêlo sem outra forma de processo. (SAUSSURE, 2004, p. 284)

Para Saussure, o signo constitui então uma entidade dinâmica, "viva", resistente tanto à imobilidade ou ao estatismo quanto ao fechamento, o que impede uma concepção positiva da sua unidade. $\mathrm{O}$ signo é em si atividade incessante, uma entidade em tensão constante, que repousa sobre um conjunto de não concordâncias: relação arbitrária entre conceitos e imagens acústicas; não coincidência entre essa primeira dualidade e a dualidade significado-significante; tensão temporal entre significante, significado e signo; pluralidade e diversidade de execuções no interior de sua identidade. O signo é, por definição e constituição, tributário dessas não concordâncias e ele as perpetua no momento de sua transmissão e de sua transformação através do tempo.

A dinâmica do signo não é nem um reflexo de outra dinâmica nem determinada por ela, mas provém de uma permanente interação entre os sistemas semióticos, psicológicos e sociais; dito de outra forma, ela é realmente uma "vida dos signos no interior da vida social".

Não há exemplo de imobilidade absoluta. Absoluto é o princípio do movimento da língua no tempo, movimento que se faz de modo diverso e mais ou menos rápido conforme o caso, mas fatalmente. (SAUSSURE, 2004, p. 268)

[...] fenômeno sócio-histórico que provoca o turbilhão de signos na coluna vertical e impede que se faça dela um fenômeno fixo ou uma linguagem convencional, já que é o resultado incessante da ação social, imposta além de qualquer escolha. (SAUSSURE, 2004, p. 92)

\section{Greimas e a enunciação em atos: manifestação, semiose, práxis}

\section{A geração e a manifestação}

Compreendendo que Hjelmslev se situa entre Saussure e Greimas, podemos consequentemente passar a um refinamento dessa dimensão prática. Com efeito, a prática semiótica (no 
sentido de operações que produzem semioses) permaneceu, em Greimas, por um longo tempo (talvez o tempo todo), nitidamente distinta da questão da enunciação. No que diz respeito a esta, sem nos estender sobre uma posição já há muito conhecida, recordemos somente que a enunciação é principalmente descrita como uma "fenda criadora" (GREIMAS; COURTÉS, 2013, p. 11), a debreagem, que projeta no discurso as categorias da pessoa, do tempo e do espaço a partir dos elementos dêiticos característicos da instância da enunciação. Ela não é uma práxis, ela é uma simples operação formal, uma ruptura de isotopia no interior das categorias que definem essa instância da enunciação.

No que diz respeito ao outro ponto, aquele da prática da produção das semioses, a teoria de Greimas é um pouco mais explícita, notadamente a propósito da "manifestação", conceito greimasiano o mais próximo daqueles que se pode mobilizar para descrever a semiose. A manifestação resulta de uma interrupção do percurso gerativo. Examinemos mais precisamente a entrada "Manifestação" do Dicionário:

Os diferentes níveis de profundidade que se podem distinguir são articulações da estrutura imanente de cada um dos dois planos da linguagem (expressão e conteúdo) tomados separadamente; esses níveis balizam seu percurso gerativo; a manifestação é, ao contrário, uma incidência, uma interrupção e um desvio, que obriga uma instância qualquer desse percurso a se constituir em um plano de signos. [...] Ao analisar as estruturas profundas e querer explicá-las com a ajuda de um sistema de representação qualquer, o linguista detém, fixa, em um dado momento, o percurso gerativo, e manifesta então as estruturas imanentes monoplanas com o auxílio de um encadeamento de signos biplanos (ou de símbolos interpretáveis). Assim também a distinção entre o discurso abstrato e o discurso figurativo pode ser estabelecida, considerada a interrupção, seguida de manifestação, do percurso gerativo em dois momentos distintos do processo de produção. (GREIMAS; COURTÉS, 2013, p. 300)

Não se trata de um incidente aleatório que afetaria o percurso gerativo do conteúdo ou da expressão, mas do princípio da manifestação que afeta sistematicamente os dois: a interrupção do processo gerativo. A interrupção não pertence à imanência e ao sistema: isso seria de fato uma hipótese absurda, visto que em Greimas o "sistema" corresponde às 
estruturas profundas virtuais e essas estruturas constituem uma parte importante do percurso gerativo. Não se vê então, na teoria de Greimas, como a interrupção do percurso gerativo poderia fazer parte do próprio percurso gerativo. Não se encontrará assim em Greimas solução tão bem articulada quanto em Saussure: a práxis, se ela existe, não é no sistema, nem no tempo da práxis e do social.

O estatuto dessa operação de interrupção do percurso gerativo não é aqui definido e só o será numa nota incidente e marginal da entrada "Enunciação" do Dicionário:

É preciso acrescentar uma última observação concernente ao que está a jusante da enunciação: enquanto ato, esta tem por efeito produzir a semiose ou, para ser mais preciso, essa sequência contínua de atos semióticos que se denomina manifestação. $\mathrm{O}$ ato de significar encontra aqui as coerções da substância da expressão, que obrigam a fazer uso de procedimentos de textualização. (GREIMAS; COURTÉS, 2013, p. 168)

A conjunção teórica é bastante explícita, mas ela foi pouco notada e ainda menos explorada pelos sucessores de Greimas: (1) o ato da enunciação (fenda criadora) que desencadeia a manifestação; (2) a semiose, oriunda da manifestação; (3) a especificação da semiose no âmbito da expressão, graças ao processo de textualização.

No que diz respeito à manifestação, notamos igualmente que ela pode ser operada pelo próprio analista, que pode interromper o percurso gerativo para alimentar sua análise com as categorias que ele extrai e que ele textualiza no discurso de sua análise. Nesse caso, a operação de interrupção da geração participa de um ato voluntário. Mas observamos também, nessa apresentação de Greimas e Courtés, que a produção de um discurso de descrição (pelo analista) não ocorre de modo distinto dos outros tipos de discurso (por exemplo: figurativo). O que faz o analista, por exemplo, textualizar diretamente as estruturas actanciais, ou os programas narrativos, sem passar por sua apresentação figurativa (atores, tempos, espaços), qualquer instância da enunciação pode fazê-lo também em outras formas de expressão.

A interrupção da geração com vistas à manifestação é então um ato por meio do qual a produção de todos os discursos é possível. Essa interrupção faz parte dos atos imputáveis ao analista, ou 
a outro ator da enunciação, e outras instâncias, involuntárias e não conscientes, podem igualmente operar. Como os dois planos da linguagem, expressão e conteúdo, estão implicados, é preciso supor duas interrupções concomitantes (ou não concomitantes), na mesma fase gerativa (ou em fases diferentes) sobre os dois percursos gerativos. Essa simples menção de uma coordenação entre duas operações de interrupção sobre os dois planos da linguagem, que não é prevista explicitamente por Greimas, abriria, no entanto, diretamente o diálogo com a concepção saussuriana que acabamos de expor, e também sobre a complexidade que se espera de uma práxis.

O raciocínio de Greimas e Courtés é aqui também tipicamente saussuriano: o plano da expressão e o plano do conteúdo podem ser analisados separadamente, do mesmo modo como os significantes e os significados abstratos e formais em Saussure, mas eles ascendem à manifestação somente pela reunião dos dois planos da linguagem por meio da semiose que lhes confere um novo modo de existência, "sobre o plano dos signos" (é o modo realizado, tal como, em Saussure, a "realidade" dos signos constituídos pela reunião do significante e do significado). Os dois planos apreendidos e estudados separadamente são imanentes, e uma vez reunidos, a semiose os "realiza".

A manifestação não é então somente uma interrupção incidente da geração imanente, ela implica também uma semiose realizante. Interrupção mais realização da semiose: a manifestação é duplamente uma saída da imanência. A questão que continua a ser posta diz respeito ao estatuto dessa "realidade": é ela interna à linguagem?

\section{A práxis enunciativa}

Outra proximidade com Saussure: do mesmo modo como neste último, as "efetuações" coletivas e massivas do sistema imanente (para a semiótica: as estruturas profundas da narratividade), que ocorrem por meio das operações constitutivas da semiose (a reunião do significante e do significado para Saussure, do plano da expressão e do plano do conteúdo para Greimas), deslocam sem cessar os dois planos um em relação ao outro: as possibilidades de interrupção do processo gerativo com vistas à semiose são somente uma parte 
${ }^{4}$ Significativamente, o primeiro tomo do Dicionário de Semiótica (2013 [1979]) não comporta nenhuma entrada "práxis" ou "práxis enunciativa". Ela só aparece no segundo tomo (1986), também sob a direção de Greimas e Courtés, mas em produção coletiva.

${ }^{5}$ Encontramos uma menção e u ma operacionalização em GREIMAS, A. J.; FONTANILLE, J. A práxis enunciativa e os primitivos. In GREIMAS, A. J. FONTA NILLE, J. Semiótica das Paixões: dos estados de coisas aos estados de alma. Tradução de Maria José Rodrigues Coracini. São Paulo: Ática, 1993, p. 79-81.

${ }^{6}$ A única coerção, na ocorrência, diz respeito ao fato de que os dois planos devem ser ao mesmo tempo "isomorfos" (eles devem apresentar formas compatíveis e associáveis) e "alótopos" (eles devem ter isotopias diferentes).

${ }^{7}$ Fontanille, J. Sémiotique et Littérature. Essais de méthode. Paris: PUF, 1999. de um conjunto mais vasto de operações que serão recobertas mais tarde ${ }^{4}$ pela denominação "práxis enunciativa" ${ }^{\prime \prime}$.

Avaliamos então toda a extensão desse potencial de operações:

(1) a cada nível do percurso gerativo, uma interrupção é possível;

(2) o número de níveis em que interrupções são possíveis não está definitivamente fixado;

(3) o modelo prevê possíveis distorções entre o que é resultante do percurso gerativo (o ser imanente) e o que é manifestado (o parecer manifestado);

(4) nada nas estruturas de cada um dos dois percursos gerativos (aquele da expressão e aquele do conteúdo) motiva, limita ou prefigura, anteriormente à reunião e à realização da semiose, a natureza e as propriedades do que será reunido ${ }^{6}$.

Podemos agora levantar a hipótese de que a práxis, para Greimas, tem sua origem nessa dupla interrupção da geração: se se supõe que as estruturas imanentes são estáveis, senão permanentes, são essas interrupções que, conduzindo à manifestação e à semiose, estão na origem da formação de configurações mais ou menos complexas, que são por sua vez estabilizadas. Essa estabilização não tem lugar no interior do sistema virtual das estruturas profundas, mas numa espécie de "enciclopédia" cultural que permanece à disposição das outras enunciações, ou que podem facilitar a automatização ulterior das operações de interrupção gerativa. Greimas não usa o conceito de enciclopédia de Umberto Eco, mas ele deve, mesmo assim, imaginar um espaço específico pertencente ao universo semiótico, que não se confunde, todavia, com o espaço das virtualidades sistêmicas: esse espaço, onde se fazem e se desfazem as coerências e as distinções culturais, é aquele dos "primitivos" (GREIMAS; FONTANILLE, 1993, p. 86-89).

A práxis enunciativa pode ser definida como "o conjunto dos atos por meio dos quais os discursos são convocados, selecionados, manipulados e inventados por cada enunciação particular"7. Ao que seria preciso acrescentar: "do ponto de vista da coletividade que assume e integra essas produções 
individuais". Pois, com efeito, a práxis enunciativa se caracteriza também, e sobretudo, por sua contribuição às inflexões e reconfigurações dos primitivos culturais. Em Sémiotica das paixões, Greimas e Fontanille definem particularmente:

A práxis enunciativa é esse ir e vir que, entre o nível discursivo e os demais, permite constituir semioticamente culturas. [...] os "primitivos" assim obtidos apresentam-se como taxinomias que, subjacentes às configurações convocadas nos discursos, aí funcionam de algum modo como conotações, distintas das denotações que resultam da convocação dos universais. Nesse sentido, a práxis enunciativa concilia um processo gerativo e um processo genético e associa no discurso os produtos de uma articulação atemporal da significação e os da história. (GREIMAS; FONTANILLE, 1993, p. 80)

Podemos notar, enfim, que em Greimas esse esboço da práxis só é explicitamente atribuído a um ator da enunciação no caso da produção dos discursos de descrição e da semiose metalinguística, enquanto nos outros casos a práxis parece operar por si só. No entanto, se há uma ou várias operações, há necessariamente uma instância operadora, isto é, um actante, mas esse actante permanece um potencial. Falar-se-á então do "impessoal" da enunciação, mas esse "impessoal" parece ter por origem a impossibilidade de atribuir a interrupção gerativa e a manifestação a quem quer que seja.

A aparição posterior do conceito de práxis enunciativa reforçará o parentesco com a massa falante de Saussure, visto que a práxis em questão não pertence a ninguém, e em se tratando dos discursos em geral, e mesmo além, de todas as semióticas-objeto possíveis, ela não é sequer associável a uma comunidade linguística. No máximo, podemos supor hoje que as formas de vida semióticas e as formas de existência sociais, e mais amplamente, as semiosferas, poderiam procurar quadros de referência para identificar aquilo que, do ponto de vida de uma semiótica geral, desempenharia o mesmo papel da massa falante de Saussure. 


\section{Perspectivas: a enunciação como sequência prática}

\section{Um campo de manobras}

Hoje, toda enunciação particular supostamente participa de um campo de manobras enunciativas mais amplo, mais geral e coletivo. Nesse sentido, ela é de imediato considerada ao menos como "re-enunciação" de enunciações anteriores ou contemporâneas. Para avançar sobre essa questão, seria necessário agora precisarmos o que é uma enunciação prática, ou melhor, uma prática de enunciação. Com efeito, se a enunciação é considerada como re-enunciação, e, mais ainda, se ela é tratada como "polifônica", ela não pode mais ser limitada ao "ato de apropriação individual da língua", mesmo se esse ato se complexifique em uma dupla interrupção do percurso gerativo da expressão e do conteúdo. A enunciação individual é só uma fase local num processo global e coletivo, e que tem sempre como consequência confirmar ou invalidar, modificar ou transformar, assumir ou recusar uma enciclopédia de primitivos semióticos que não é de natureza individual.

Consequentemente, a enunciação deve ser examinada sobre outro plano de imanência diferente daquele da textualidade. Numa concepção estritamente textualista, a enunciação é apenas o ato de apropriação individual da língua, no sentido de que ela produz um texto particular a partir do sistema linguístico e semiótico do qual dispõe. Mas não se pode fundar uma enunciação coletiva, polifônica, multidimensional e evolutiva sobre o único plano de imanência da textualidade: ela é necessariamente de ordem processual e prática, e é essa a razão pela qual Greimas havia escolhido denominá-la "práxis" enunciativa.

Nesse estágio da reflexão, podemos dispor dos seguintes elementos:

(1) Toda enunciação pressupõe, explora e manifesta uma ou mais experiências, anteriores, posteriores ou concomitantes.

(2) Essas experiências podem ser somáticas, práticas, textuais ou de outros tipos: midiáticas, científicas, sobretudo.

(3) Elas podem ter sido assumidas explicitamente por outras enunciações cujos atos e autores são identificáveis 
(nesses casos há, no sentido estrito, enunciação depois re-enunciação), mas elas podem igualmente ter sido somente memorizadas, partilhadas ou transmitidas, no interior de uma experiência individual ou coletiva, sem enunciação identificável. Em todos os casos, essas experiências já produziram semioses textuais, práticas ou existenciais.

(4) A experiência em questão é acessível a uma exploração reflexiva, e suficientemente maleável para ser transposta em outra semiose.

O conjunto dessas condições constitui a enunciação como uma prática específica, uma prática de produção de semioses a partir da experiência. Nós podemos então tentar propor uma sequência canônica da enunciação prática.

\section{A sequência prática da enunciação}

Na sua última obra sobre os modos de existência, Bruno Latour (2012) propõe considerar que o sentido advém no mundo da existência por instauração, operação que é definida a minima pela intensificação e extensão da presença, sem que seja necessário colocar previamente um actante sujeito ao qual seria atribuída uma enunciação. A instauração só é atribuível a um estado de coisas dinâmico, uma instância difusa e em curso de emergência.

No que se refere mais particularmente às práticas, elas ganham sentido porque continuam seu curso apesar dos obstáculos e das resistências (em extensão) e porque elas só podem fazê-lo em razão de uma força de engajamento que mantém esse curso prático (em intensificação). Aqui também, essa instauração extensiva e intensiva só pode ser atribuída a uma instância difusa, plural e em movimento. A instauração é assim a forma primária da enunciação prática. Há enunciação porque a significação emerge da dinâmica de um curso de ação e da atividade de uma instância que está ela mesma em curso de instauração.

Alguma coisa se instaura, mas a partir do quê? Por transformação ou conversão de qual outra coisa? Se a instauração não é uma operação mágica que suscita o sentido ex nihilo, supõe-se que ela transforma alguma coisa cuja significação 
ainda não é acessível em outra coisa que é um conjunto significante. A manifestação significante e instaurada seria a transformação do quê? Nossa resposta: ela é a transformação da experiência. A experiência humana em busca de sua significação torna-se uma prática semiótica na medida em que ela mesma é acessível à experiência: essa reflexividade elementar é o ponto de partida e a condição mínima do questionamento do sentido. É precisamente nessa experiência reflexiva que são percebidas e apreendidas a intensidade e a extensão, necessárias para que haja "instauração".

A enunciação-instauração do sentido prático transforma a experiência em manifestação significante: resta descrever agora essa mediação enunciativa. Precisemos primeiramente que a prática de enunciação não pode ser uma prática social ou individual como as outras: ela não só produz sentido, o que não é o caso de toda prática, mas ela também o enuncia, e produz uma semiose em boa e devida forma.

A primeira articulação da experiência será então uma reflexão: nessa instauração-enunciação específica, praticar procura o sentimento de praticar. Num extremo e no outro do predicado "procura o sentimento", o primeiro "praticar" é afetante, e o segundo é afetado. A reflexão elementar, no curso da prática, é um afeto. Em outros termos, o afeto emerge em duas fases simultâneas ou sucessivas: praticar e sofrer a prática. Alguma coisa toma forma na ação, e o afeto retoma isso reflexivamente. No âmago da experiência, assiste-se então à "tomada de forma" e à "retomada". Desse ponto de vista, toda práxis enunciativa comporta, como vimos, uma capacidade de estabilização ou de desestabilização de formas, em suma, procedimentos que garantem o reconhecimento das fases e dos momentos do curso prático. A reflexão forma e deforma os esquemas e modelos. Tomada e retomada são os dois momentos elementares da fase reflexiva da enunciação considerada como uma práxis.

A segunda articulação é a resposta a esse afeto: o afeto reflexivo é uma demanda de sentido, à qual responde uma exploração desse afeto, de que resulta uma semiose, a produção de uma semiótica-objeto. Essa semiose pode adotar uma grande diversidade de planos de expressão, alternativa ou sucessivamente: a exploração enunciativa se completa então de uma ou várias transposições em diferentes expressões; a 
experiência pode ser, por exemplo, olfativa, ou emocional, e sua exploração pode conduzir a semioses textuais ou visuais.

A exploração esquematiza e transpõe uma experiência. Para fazê-lo, ela deve, a princípio, extrair e explorar simultaneamente as propriedades dessa experiência, e convertêlas em dependências internas próprias a uma semiótica-objeto. Além disso, ela intensifica, desdobra e especifica o afeto prático: ela solicita o provado na experiência para extrair os esquemas e propriedades, para suscitar respostas e explorar essas respostas ao transpô-las de uma substância a outra.

Esse processo é particularmente colocado em evidência, por exemplo, quando se trata de visualizar as propriedades "invisíveis" de um corpo ou de um sistema físico qualquer: as imagens científicas dão prova, nesse sentido, de uma notável inventividade técnica para responder a todos os casos de invisibilidade e de inacessibilidade: as interações matérias/ energias solicitam o sistema físico para obter respostas (os sinais de diversas naturezas técnicas), que são elas mesmas submetidas à transposição substancial que as faz aceder a uma semiose visual. Os produtos dessas "explorações" sofisticadas são evidenciados pela esquematização, bem como pela espacialização, pela temporalização, até a visualização final.

A exploração da experiência pela enunciação prática comporta ao menos:

(1) uma fase de interação e de excitação dos objetos da experiência para extrair propriedades exploráveis (informação, sinais, qualidades sensíveis ou físicas);

(2) uma fase de transposição dessas propriedades e desses produtos da interação/ excitação primária nas propriedades correspondentes de um domínio semiotizável (transdução informática, projeção sobre um suporte, organização plástica, etc.);

(3) uma fase de manifestação semiótica (conteúdo + expressão), que se traduz pela produção de uma semiótica-objeto sobre seu próprio suporte e segundo suas próprias regras de organização e interpretação.

É assim que a dupla sequência de reflexão e de exploração garante a mediação entre a experiência primária e a semiótica-objeto. 


\section{REFERÊNCIAS}

BERTRAND, D. L'impersonnel de l'énonciation. In: BERTRAND; MILOT (éds.). Schémas. Protée. Théories et pratiques sémiotiques: Chicoutimi: Université de Chicoutimi, v. 21, n. 1, p. 25-32, 1993.

BASSO-FOSSALI, P. (ed.) Testo, pratiche, immanenza. Semiotiche: Torino, n5, 2006. Disponível em: <http://www. fonurgia.unito.it/andrea/pub/semiotiche5.pdf $>$. Acesso em: 11 de abril de 2017.

BRONCKART, J-P. L'analyse du signe et la genèse de la pensée consciente. In Cahiers de l'Herne n ${ }^{\circ}$ 76: Saussure. L'Herne: Paris, 2003, p. 94-107.

BULEA, E. Linguistique saussurienne et paradigme thermodynamique. Cahier de la Section des Sciences de l'éducation. Genève: Université de Genève, nº104, 2005, p. 53-186, 2005.

BULEA, E. Est-ce ainsi que les signes vivent? Paris: Texto!, vol. X, n4, 2005. Disponível em: <http://www.revuetexto.net/Saussure/Sur_Saussure/Bulea_Signes.html>. Acesso em: 11 de abril de 2017.

COQUET, J-C. Le discours et son sujet. Paris: Klincksieck, 1984. DONDERO, M. G.; Fontanille, J. Des images à problèmes. Le sens du visuel à l'épreuve de l'image scientifique. Pulim: Limoges, 2012.

FEHR, J. La vie sémiologique de la langue : esquisse d'une lecture des Notes Manuscrites de Saussure. Paris: Langages, $\mathrm{n}^{\circ} 107$, p. 73-83, 1992.

FONTANILLE, J. Sémiotique et littérature. Essais de méthode. Paris: PUF, 1999.

. Pratiques sémiotiques. Paris: PUV, 2008.

;ZILBERBERG, CL. Tensão e significação. Tradução de Ivã

Carlos Lopes, Luiz Tatit e Waldir Beividas. São Paulo: Discurso Editorial: Humanitas/FFLCH/USP, 2001.

GREIMAS, A. J.; COURTÉS, J. Sémiotique. Dictionnarie raisonné de la théorie du langage. Tome 2. Paris: HACHETTE, 1986.

.; FONTANILLE, J. Semiótica das Paixões: dos estados de coisas aos estados de alma. Tradução de Maria José Rodrigues Coracini. São Paulo: Ática, 1993. 
GREIMAS, A. J.; COURTÉS, J. Dicionário de Semiótica. Tradução de Alceu Dias Lima et al. 2. ed. São Paulo: Contexto, 2013.

GODEL, Robert. Les sources manuscrites du cours de linguistique générale de F. de Saussure. 2.ed. Genève: Droz, 1957.

HJELMSLEV, L. Prolegômenos a uma teoria da linguagem. Tradução de José Teixeira Coelho Neto. 2. ed. São Paulo: Perspectiva, 2013. SAUSSURE, F. Curso de Linguística Geral. Tradução de Antônio Chelini, José Paulo Paes, Izidoro Blikstein. 27. ed. São Paulo: Cultrix, 2006.

Escritos de Linguística Geral. Tradução de Carlos Augusto Leuba Salum e Ana Lúcia Franco. São Paulo: Cultrix, 2004.

\section{Abstract \\ Praxis and enunciation: Greimas, heir of Saussure}

Having as a starting point Saussure's studies on the sign and the praxis dimension of language, this article discusses the organization of a theory of semiotic enunciation and, more precisely, the concept of enunciative praxis. Such notion refers to the operations that, by assuming the system of narrative deep structures, produce semiotic configurations sufficiently stabilized to be available for other uses. These configurations are understood in a constant movement of reshaping of forms, which is therefore responsible for discourse renewal.

Keywords: Saussure. Greimas. Semiotic. Linguistic sign. Enunciative praxis. 